\section{Author Reply: Patients with Familial Adenomatous Polyposis}

With great interest we read the letter by Cetta et al. reporting on extensive personal experience in familial adenomatous polyposis (FAP) patients with thyroid carcinomas, liver tumors, and brain tumors.

Cetta and coworkers suggest, based on their own data, the restriction of thyroid surveillance to patients with CHRPE or APC mutations before codon 1220. We would like to emphasize that the population at risk is described in our manuscript by genotype-phenotype relationship as depicted in Fig. 1. ${ }^{1}$ When the mutation is not known, the demographic characteristics of the population that should undergo surveillance are described in Table 1. Palpation of the neck is easy to perform and not time consuming. If applied in all FAP patients, it has the advantage that this simple and noninvasive procedure will be surely applied in those who really are at risk. Indeed, the optional ultrasound can be used in the subgroups as suggested by Cetta.

Regarding the comments given by Cetta et al. on genotype-phenotype correlations in hepatoblastoma, we would like to draw attention to the legend in our Fig. 1. The margins of codon regions associated with extraintestinal manifestations are not absolute. Nevertheless, we are aware that Hirschman et al. have found mutations between codons 141 and 1750, as we have pointed out in the written text. ${ }^{2}$ We would like to underline that excessively relying on exact boundaries of genotype-phenotype relationships is not advisable. They merely provide a guideline.

Further, Cetta et al. suggest other types of liver tumors in FAP besides hepatoblastoma. Indeed, hepatocellular carcinomas (HCC) in FAP patients have been described in some case reports. ${ }^{3-8}$ These cases were assumingly not associated with a history of hepatitis or alcoholism. Although in some of them a confirmed germline mutation of the APC gene was noted, no further information on tumor characteristics (e.g., loss of heterozygosity) was given. The association of hepatocellular carcinoma and FAP may not be coincidental as hepatocellular carcinoma is also a tumor with frequent aberrant activation of $\beta$-catenin signaling. ${ }^{9-11}$ Nuclear or cytoplasmic accumulation of $\beta$-catenin has been observed in 33\%-67\%, although mutations of APC and/or $\beta$ catenin genes were only found in about $20 \%-30 \%$ of HCCs, suggesting that the predominant mechanism(s) and signaling pathways may be different from that found in colorectal cancers. ${ }^{11}$ We agree with the recommendations made by Gruner et al. that APC gene mutation testing is warranted in the absence of a clear etiology for HCC in children and adolescents (e.g., hepatitis B), if there is a strong family history of colon cancer or if the patient develops known extraintestinal manifestations of FAP. ${ }^{3}$ However, the number of case reports is not that impressive and the relationship may be due to chance. A similar situation is seen in adrenocortical carcinomas associated with FAP. These are very rare and to our knowledge only six cases have been described. ${ }^{12}$ Therefore, HCC is not generally considered to be a manifestation of FAP syndrome.

With regard to brain tumors, we appreciate the efforts of Cetta to gain more insight into patients at risk. In fact, national polyposis registries may have an additional important role to extend this work and collect data on gene mutations and histology of brain tumors. For now, data on brain tumors other than medulloblastomas are scarce. It is interesting to suggest intensive screening for brain tumors in patients with mutations between codon 140 and 1220 from age $2 .^{13}$ What kind of surveillance protocol would suffice in FAP patients, not only from the perspective of early detection of brain tumors, but also from feasibility especially at a very young age? As far as we know, no detailed protocol suggestions have been published. With great interest we await the results of such a surveillance study (or the description of personal experience) on the feasibility, effectiveness, and clinical benefit. Meanwhile, we would emphasize FAP families and their doctors to be aware of clinical signs and symptoms of brain tumors. Heightened suspicion may be warranted for mutations between codons 140 and 1220 , but this remains to be established.

Emma J. Groen, MD ${ }^{1}$, Annemieke Roos, MD', Friso L. Muntinghe, $\mathrm{MD}^{2}$, Roelien H. Enting, $\mathrm{MD}, \mathrm{PhD}^{3}$, Jakob de Vries, MD, $\mathrm{PhD}^{4}$, Jan H. Kleibeuker, $\mathrm{MD} \mathrm{PhD}^{5}$, Max J. H. Witjes, MD, PhD ${ }^{6}$, Thera P. Links, MD, PhD ${ }^{1}$, and André P. van Beek, MD, PhD ${ }^{1}$ 
${ }^{1}$ Department of Endocrinology, University Medical Center Groningen, University of Groningen, Groningen,

The Netherlands;

${ }^{2}$ Department of Internal Medicine, University Medical

Center Groningen, University of Groningen, Groningen,

The Netherlands;

${ }^{3}$ Department of Neurology, University Medical Center

Groningen, University of Groningen, Groningen,

The Netherlands;

${ }^{4}$ Department of Surgery, University Medical Center

Groningen, University of Groningen, Groningen,

The Netherlands;

${ }^{5}$ Department of Gastroenterology, University Medical

Center Groningen, University of Groningen, Groningen,

The Netherlands;

${ }^{6}$ Department of Oral and Maxillofacial Surgery, University

Medical Center Groningen, University of Groningen,

Groningen, The Netherlands;

e-mail: a.p.van.beek@int.umcg.nl

Published Online: 4 March 2009

(C) The Author(s) 2009. This article is published with open access at Springerlink.com

OPEN ACCESS This article is distributed under the terms of the Creative Commons Attribution Noncommercial License which permits any noncommercial use, distribution, and reproduction in any medium, provided the original author(s) and source are credited.

\section{REFERENCES}

1. Groen EJ, Roos A, Muntinghe FL, R.H. Enting, J. de Vries, J.H. Kleibeuker, et al. Extra-intestinal manifestations of familial adenomatous polyposis. Ann Surg Oncol 2008;15:2439-50.
2. Hirschman BA, Pollock BH, Tomlinson GE. The spectrum of APC mutations in children with apparently sporadic hepatoblastoma be screened for APC gene mutations? Pediatr Blood Cancer 2005; $147: 263-6$.

3. Gruner BA, DeNapoli TS, Andrews W, Tomlinson G, Bowman L, Weitman SD. Hepatocellular carcinoma in children associated with Gardner syndrome or familial adenomatous polyposis. J Pediatr Hematol Oncol 1998;20:274-8.

4. Weinberger JM, Cohen Z, Berk T. Polyposis coli preceded by hepatocellular carcinoma: report of a case. Dis Colon Rectum 1981;24:296-300.

5. Zeze F, Ohsato K, Mitani H, Ohkuma R, Koide O. Hepatocellular carcinoma associated with familial polyposis of the colon: report of a case. Dis Colon Rectum 1983;26:465-8.

6. Laferla G, Kaye SB, Crean GP. Hepatocellular and gastric carcinoma associated with familial polyposis coli. J Surg Oncol 1988;38:19-21.

7. Van Steenbergen W, Fevery J, De Groote J, Baert A, Desmet V, Van Eyken P. Hepatocellular carcinoma in a case of familial polyposis coli. Am J Gastroenterol 1989;84:1120-1.

8. Montalto G, Cetta F, Gori M, et al. Deregulation of the APC-wnt$\beta$-catenin signaling in hepatoblastoma (HB) and hepatocellular carcinoma (HCC) occurring at different ages in the same patient with familial adenomatous polyposis (FAP). Tumori 2001;3: 70-87.

9. Buendia MA. Genetic alterations in hepatoblastoma and hepatocellular carcinoma: common and distinctive aspects. Med Pediatr Oncol 2002;39:530-5.

10. Lee HC, Kim M, Wands JR. Wnt/Frizzled signaling in hepatocellular carcinoma. Front Biosci 2006;11:1901-15.

11. Buendia MA. Genetics of hepatocellular carcinoma. Semin Cancer Biol 2000;10(3):185-200.

12. Roos A, Groen EJ, van Beek AP. Cushing's syndrome due to unilateral multiple adrenal adenomas as an extraintestinal manifestation of familial adenomatous polyposis. Int J Colorectal Dis. 2009; 24; Epub ahead of print: 2008 Aug 22.

13. Cetta F, Dhamo A. Inherited multitumoral syndromes including colorectal carcinoma. Surg Oncol 2007;16:S17-S23. 